\author{
Military Technical College \\ Kobry El-Kobbah, \\ Cairo, Egypt.
}

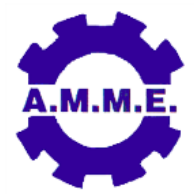
$17^{\text {th }}$ International Conference on Applied Mechanics and Mechanical Engineering.

\title{
EXPERIMENTAL EVALUATION OF CONDENSATION HEAT TRANSFER COEFFICIENT OF R-417A IN HORIZONTAL TUBES
}

\author{
R. Gendy ${ }^{1}$, E. Elgendy ${ }^{2}$, H. Mahmoud ${ }^{2}$ and A. B. Helali ${ }^{3}$
}

\begin{abstract}
In this paper, condensation heat transfer coefficients (HTCs) of R-417A in horizontal smooth and micro-fin tubes under different parameters such as refrigerant saturated vapor temperatures (dew point) $\left(40-60^{\circ} \mathrm{C}\right)$, cooling water inlet temperature $\left(15-30^{\circ} \mathrm{C}\right)$, cooling water velocity $\left(0.65-0.85 \mathrm{~ms}^{-1}\right)$ have been investigated. Predicted HTCs in smooth tube are within $\pm 20 \%$ as compared with literature correlations for R-22 and R417A respectively. Condensation HTCs decreased by $58 \%$ as the condensation temperature increased from 40 to $60^{\circ} \mathrm{C}$ at constant water temperature of $25^{\circ} \mathrm{C}$. Cooling water inlet temperature has the most significant impact on condensation HTCs where condensation HTCs increased from 1.6 to $5.6\left(\mathrm{kWm}^{-2} \mathrm{~K}^{-1}\right)$ as the cooling water inlet temperature changed from 15 to $30^{\circ} \mathrm{C}$ at refrigerant saturated vapor temperature of $40^{\circ} \mathrm{C}$. It should be pointed out, condensation HTCs decreased by $32.3 \%$ and $15.3 \%$ using R-417A as compared with R-22 at saturation temperatures of $40^{\circ} \mathrm{C}$ and $60^{\circ} \mathrm{C}$ at cooling water inlet temperature of $15^{\circ} \mathrm{C}$.
\end{abstract}

\section{KEY WORDS}

R-22 Condensation; R-417A Condensation; R-22-alternatives; Horizontal smooth, Micro-finned tubes.

1 Graduate Student, Mechanical Power Engineering Department, Faculty of Engineering at El-Mattaria, Helwan University, Egypt.

2 Assistant Professor, Mechanical Power Engineering Department, Faculty of Engineering at El-Mattaria, Helwan University, Egypt.

3 Professor, Mechanical Power Engineering Department, Faculty of Engineering at ElMattaria, Helwan University, Egypt. 


\section{NOMENCLATURE}

$\begin{array}{ll}\text { A } & \text { surface area }\left(\mathrm{m}^{2}\right) \\ \mathrm{C} & \text { specific heat at constant pressure }\left(\mathrm{kJ} \mathrm{kg}^{-1} \mathrm{~K}^{-1}\right) \\ \mathrm{D}, \mathrm{d} & \text { diameter }(\mathrm{m}) \\ \mathrm{g} & \text { gravitational acceleration }\left(\mathrm{m} \mathrm{s}^{-2}\right) \\ \mathrm{h} & \text { heat transfer coefficient }\left(\mathrm{kW} \mathrm{m}^{-2} \mathrm{~K}^{-1}\right) \\ \mathrm{LH} & \text { latent heat }\left(\mathrm{kJ} \mathrm{kg}^{-1}\right) \\ \mathrm{k} & \text { thermal conductivity }\left(\mathrm{kW} \mathrm{m}^{-1} \mathrm{~K}^{-1}\right) \\ \mathrm{L} & \text { effective tube length }(\mathrm{m}) \\ \Delta T_{l m} & \text { logarithmic mean temperature difference }\left({ }^{\circ} \mathrm{C}\right) \\ \dot{m} & \text { mass flow rate }\left(\mathrm{kg} \mathrm{s}^{-1}\right) \\ \mathrm{n} & \text { number of fins } \\ \mathrm{Nu} & \text { Nusselt number } \\ \mathrm{Re} & \text { Reynolds number } \\ \mathrm{P} & \text { pressure }(\mathrm{kPa}) \\ \mathrm{Pr} & \text { Prandtl numbers } \\ \mathrm{q} & \text { heat flux }\left(\mathrm{kW} \mathrm{m} \mathrm{m}^{-2}\right) \\ \mathrm{Q} & \text { heat transfer rate }(\mathrm{kW}) \\ \mathrm{Sk} & \text { fin thickness }(\mathrm{mm}) \\ \mathrm{t} & \text { height fins }(\mathrm{mm}) \\ \mathrm{T} & \text { temperature }\left({ }^{\circ} \mathrm{C}\right) \\ \mathrm{U} & \text { overall heat transfer coefficient }\left(\mathrm{kW} \mathrm{m}^{-2} \mathrm{~K}^{-1}\right) \\ \mathrm{V} & \text { velocity }\left(\mathrm{m} \mathrm{s}^{-1}\right) \\ \mathrm{X} & \text { vapor quality } \\ \end{array}$

\begin{tabular}{ll}
\multicolumn{2}{l}{ SUBSCRIPTS } \\
a & actual \\
con & condensation \\
cond & condenser \\
h & hydraulic \\
I & fluid phase \\
m & mean \\
i & inside \\
o & outside \\
r & refrigerant \\
s & surface \\
sub & subcooled \\
sl & saturated liquid \\
t & tube \\
v & vapor phase \\
w & water
\end{tabular}

\section{ABBREVIATIONS}

EES engineering equation solver

HCFC hydrochlorofluorocarbon

HFC hydrofluorocarbon

HTCs heat transfer coefficients

\section{GREEK SYMBOLS}

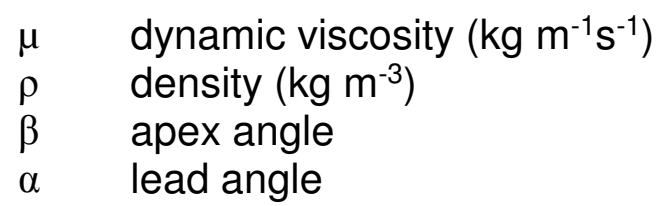

\section{INTRODUCTION}

Condensers and evaporators play an important role in performance and physical size of air conditioning and heat pump systems. Hence, condensation heat transfer coefficients (HTCs) of a working fluid in tubes are vital in design procedure of condensers. Since many decades, R-22 has been used in refrigeration and air conditioning systems. However, it belongs to the family of hydro-chlorofluorocarbon (HCFC) refrigerants which have been considered as harmful working fluids to environment and have been controlled by the Montreal protocol [1-2]. According to this protocol, R-22 was described as an intermediate substitute and allowed to be used until 2030 by developed countries and 2040 by developing ones [3]. Therefore, attention of many researchers has been focused on finding an alternative to R-22.

$\mathrm{R}-407 \mathrm{C}$ and $\mathrm{R}-410 \mathrm{~A}$ are used as replacements for $\mathrm{R}-22$ in air conditioning and medium temperature applications, while R-404A and R-507 are used in the low temperature applications. Regarding to air conditioning and medium temperature applications, 
Uchida et al. [4] performed an experimental study on R-407C condensation and evaporation in smooth, single and cross-grooved tubes. They reported that HTCs for cross-grooved tubes are over three times compared with those of smooth tube and 20-40\% larger than those for single grooved tubes, respectively. Wijaya and Spatz [5] conducted an experimental study on condensation heat transfer of R-410A in a horizontal smooth tube and compared the results with R-22 data. They presented that the condensation HTCs and pressure drops for R-410A were 2-6\% higher and 25$45 \%$ lower, respectively, than those for R-22. Local and average condensation HTCs for seven micro-fin tubes were presented and compared with smooth tube using R-22 and R-410A by Kim and Shin [6]. Average condensation HTCs of R-22 and R-410A for micro-fin tubes were 1.7-3.19 and 1.7-2.94 times larger than those for smooth tube. Jung et al. [7] carried out flow condensation experiments using R-22, R-134a, R-407C, and R-410A inside horizontal smooth and micro-fin tubes. They reported that R-134a showed lower HTCs with the smooth tube while R-407C and R-410A showed lower HTCs with the micro-fin tube.

Regarding to low temperature applications, Infante Ferreira et al. [8] determined the condensation HTCs and pressure drop of R-404A inside horizontal tubes with smooth, micro-fin, and cross-hatched tubes. They obtained the heat transfer enhancement ratio of $80-140 \%$ for both micro-fin and cross-hatched tubes. Followed this study, Sapali and Patil [9] carried out an experiment work to evaluate condensation HTCs for R-134a and $\mathrm{R}-404 \mathrm{~A}$ in smooth and micro-fin tubes at various refrigerant saturated temperatures ranging from $35^{\circ} \mathrm{C}$ to $60^{\circ} \mathrm{C}$. Average condensation HTCs of R-134a and R-404A for micro-fin tubes are 1.5-2.5 and 1.3-2 times larger than that in smooth tube respectively.

Recently, a drop-in refrigerant to substitute $\mathrm{R}-22$ in existing plants to continue its remaining life with minor modifications is mostly economically. In this situation, mixtures consisted of the natural and synthetic refrigerants are standing out as longterm drop-in alternative refrigerants Yang et al. [10]. Among these refrigerants, R-417A (HFC-134a/HFC-125/HC-600, 0.5/0.466/0.034 by mass) is non-ozone depleting longterm replacement and belong to the safest group (A1) in ASHRAE classifications. Moreover, R-417A can be adopted in existing small, direct expansion, residential and commercial air conditioning equipment with minor modifications. Furthermore, R-417A is compatible with traditional and new lubricants, providing easy, quick, cost effective retrofits and can be topped up during service without removing the entire refrigerant charge [11]. Boissieux et al. [12] reported experimental local condensation HTCs for R-404a, R-407C and R-417A in a horizontal smooth tube and compared their results with Dobson and Chato [13] and Shah [14] correlations. Their results confirmed that Dobson and Chato [13] correlation gave the best prediction of the three considered refrigerants. However, to the best of our knowledge, there are not available data on the effect of cooling medium temperature, cooling medium velocity and refrigerant saturated vapor temperature on the condensation HTCs for the drop-in alternative refrigerant. Hence, the present article aims to evaluate the condensation HTCs of R$417 \mathrm{~A}$ in smooth and micro-fin tubes under different operating parameters such refrigerant saturated vapor temperature, cooling water inlet temperature and cooling water velocity. 


\section{EXPERIMENTAL APPARATUS}

Figure 1 shows a schematic diagram of the test rig, which consists mainly of two circuits namely; a refrigerant circuit and a cooling water circuit with necessary instrumentations. The refrigerant circuit contains a boiler, a water cooled condenser (test section), a sight glass and control valves. The boiler constructed of a stainless steel tube of $140 \mathrm{~mm}$ outside diameter and $800 \mathrm{~mm}$ length and equipped with two electric band heaters at the bottom of the boiler. The upper one is $140 \mathrm{~mm}$ height and $1.7 \mathrm{~kW}$ and the lower one is $90 \mathrm{~mm}$ height and $1.4 \mathrm{~kW}$. The power of electric heaters is controlled via two variable voltage devices, each of $2 \mathrm{kVA}$. Two valves are installed on the boiler, one on the upper flange $\left(V_{4}\right)$ for charging and evacuation purposes and the other on the lower flange $\left(V_{5}\right)$ for drain. A non-return valve $\left(V_{1}\right)$ is connected to the refrigerant vapour line, downstream the sight glass, to prevent back flow from the boiler. Two wells of different lengths are inserted inside the boiler at different levels to allow liquid $\left(T_{1}\right)$ and vapor $\left(T_{2}\right)$ temperature measurements.

The test section is a double tube heat exchanger in which cooling water flows in the annular space while the refrigerant condensates inside the tube. The outer tube is made of brass with a nominal outside/inside diameters of $28.58 / 25.28 \mathrm{~mm}$ while the inner tube is made of copper and has a nominal outside/inside diameters of 12.7/10.22 $\mathrm{mm}$ and 9.52/8.84 $\mathrm{mm}$ for smooth and micro-finned pipes respectively. The test section length is $1000 \mathrm{~mm}$ and is insulated from the surroundings by $15 \mathrm{~mm}$ thick glass wool. The test section is equipped with two valves $\left(\mathrm{V}_{1}\right.$ and $\left.\mathrm{V}_{2}\right)$ at its inlet and exit for handling purposes. Fig. 2 shows schematic diagram of the test section.

The cooling water circuit is used to supply water to the test section for condensation of the refrigerant. It consists of a water tank of $250 \mathrm{~L}$ capacity, a circulating pump and a test section. The cooling water flow rate is adjusted via valve $\left(V_{6}\right)$ on the main water line and valve $\left(\mathrm{V}_{7}\right)$ on the by-pass line. In order to provide a fine control of the cooling water temperature, the water tank is equipped with a refrigeration unit of $3.5 \mathrm{~kW}$ capacity and two immersed electric heaters (total power of $4 \mathrm{~kW}$ ). The cooling water circuit is thermally insulated by a glass wool.

Temperature, pressure and flow rate measuring locations are also shown in Fig. 1. Calibrated thermocouples (Type-K) are used to measure refrigerant and water temperatures at inlets and outlets of test section (4 points). Accuracy of the temperature measurements is within $\pm 0.25 \%$. Calibrated pressure transducers are mounted on the condenser $\left(P_{1}, P_{2}\right)$ and the boiler $\left(P_{3}\right)$ in order to measure their vapor pressures. The accuracy of pressure transducer measurements is within $\pm 0.3 \%$.

The thermocouples and pressure transducers are connected to a data acquisition card of 16 channels. The mass flow rate of cooling water is measured with a turbine flow meter within $0.3 \%$. The entire assembly of the refrigerant circuit is tested for leakage under a pressure of $3.0 \mathrm{MPa}$ for $24 \mathrm{hrs}$. Then, it is evacuated using a vacuum pump to remove any moisture or non-condensable gases that may exist in the system. Finally, the required quantity of refrigerant liquid is charged into the boiler. The same procedure is used for R-417A and R-22. The experiments were performed over a wide range of operating parameters. The experimental test conditions are listed in Table 1. 


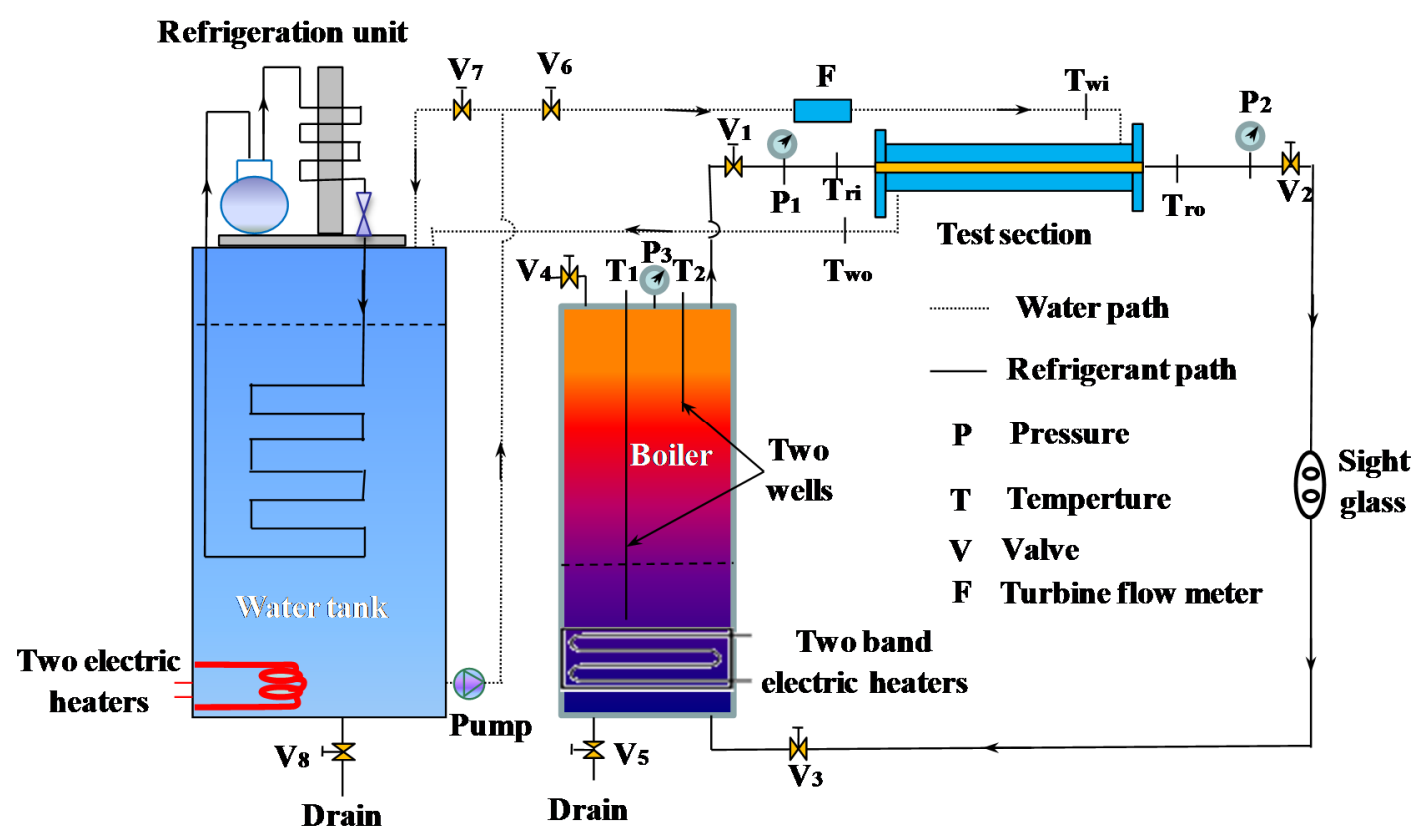

Fig. 1. Schematic diagram of the test rig.

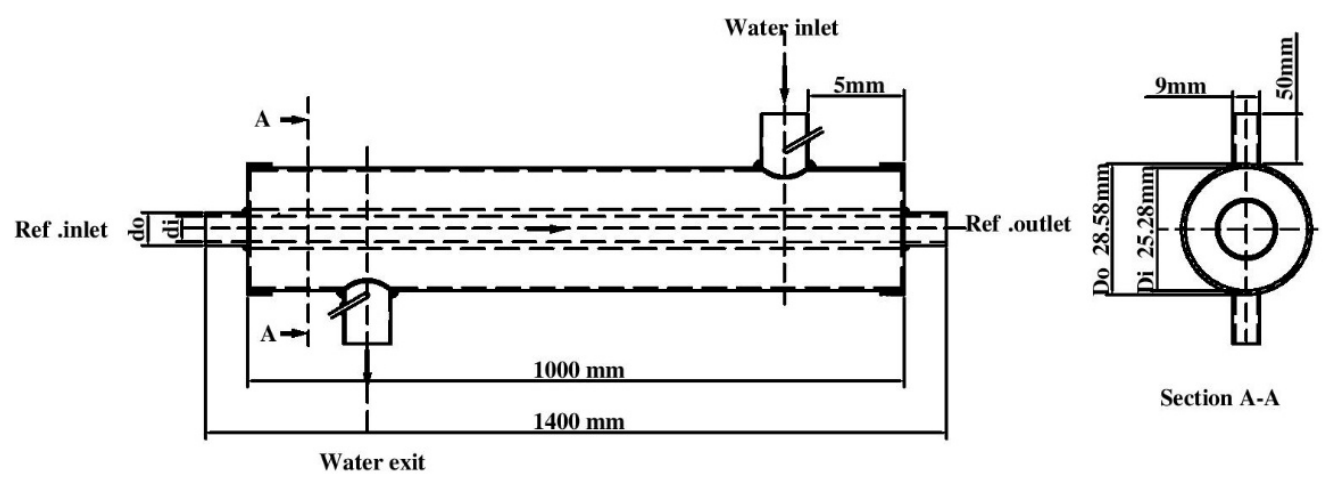

(a) Test section

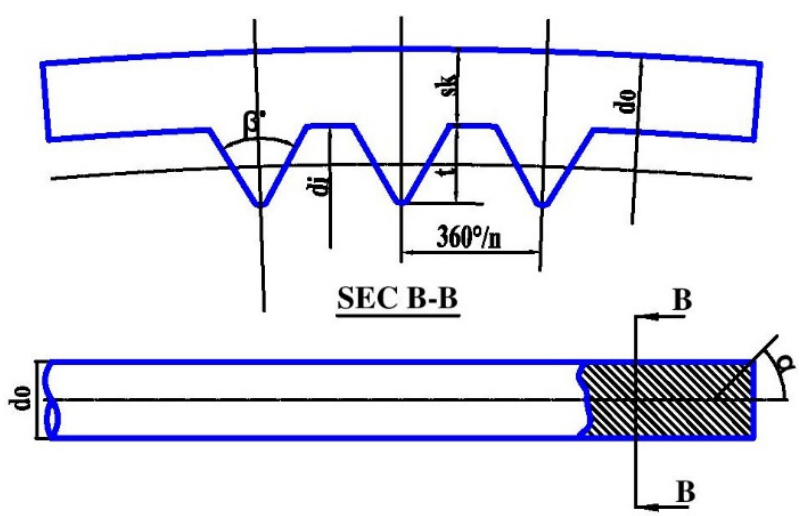

\begin{tabular}{l|l}
\hline Parameter & Dimension \\
\hline $\mathrm{d}_{\mathrm{o}}$ & $9.52 \mathrm{~mm}$ \\
$\mathrm{~d}_{\mathrm{i}}$ & $8.98 \mathrm{~mm}$ \\
$\mathrm{t}$ & $0.2 \mathrm{~mm}$ \\
$\mathrm{sk}$ & $0.34 \mathrm{~mm}$ \\
$\beta$ & $40^{\circ}$ \\
$\alpha$ & $18^{\circ}$ \\
$\mathrm{n}$ & 60 \\
\hline
\end{tabular}

(b) Cross section of the micro-fin tube

Fig. 2. Schematic diagram of the test section. 
Table 1. Experimental test conditions.

\begin{tabular}{ll}
\hline Parameters & Range \\
\hline Refrigerant type & R-417A and R-22 \\
Refrigerant saturated vapor temperature $\left({ }^{\circ} \mathrm{C}\right)$ & $40-45-50-55-60$ \\
Water inlet temperature $\left({ }^{\circ} \mathrm{C}\right)$ & $15-20-25-30$ \\
Water velocity $\left(\mathrm{ms}^{-1}\right)$ & $0.95-0.85-0.75-0.65$ \\
Tube inner surface & Smooth and micro-fin tubes \\
\hline
\end{tabular}

Experimental procedure is started by adjusting the cooling water temperature to a predetermined value. Then, the cooling water flow rate and the electric power to the boiler heaters are adjusted to obtain the required saturation pressure (or temperature). The system runs until steady state conditions are reached. Then, pressures, temperatures and flow rates are recorded.

Each run was repeated three times and the average value was used in the data reduction. It should be mentioned that care has been taken to ensure that the measured temperatures of the refrigerant and those corresponding to the measured saturation pressures are nearly equal during all runs. Thus, the inlet vapor quality is 1 and the effect of superheating has been ignored. Table 2 shows the uncertainty values of the experimental parameters.

\section{DATA REDUCTION}

It should be noted that the condenser is analyzed as two zones namely, condensation and subcooled zone. In condensation zone the refrigerant vapor is converted to saturated liquid while in subcooled zone it is converted into subcooled liquid state, i.e.

$$
Q_{\text {cond }}=Q_{\text {con }}+Q_{\text {sub }}
$$

where $Q_{\text {cond }}$ is the condenser heat transfer rate and can be determined by a simple energy balance equation as follows;

$$
Q_{\text {cond }}=Q_{w}=\dot{m}_{w} c_{w}\left(T_{\text {wo }}-T_{w i}\right)
$$

where $\dot{m}_{w}$ is the water mass flow rate, $c_{w}$ is the specific heat of water, $T_{w i}$ and $T_{w o}$ are the inlet and outlet water temperatures, respectively. Therefore, the refrigerant mass flow rate can be calculated using the following equation;

$$
\dot{m}_{\text {ref }}=Q_{\text {cond }} /\left(h_{r i}-h_{\text {ro }}\right)
$$


Table 2. Uncertainty values of the experimental parameters.

\begin{tabular}{lll}
\hline No & Parameters & \% Uncertainty \\
\hline 1 & Refrigerant temperature $\left(\mathrm{Tr}_{\mathrm{r}}\right)$ & 0.25 \\
2 & Refrigerant pressure $\left(\mathrm{P}_{\mathrm{r}}\right)$ & 0.3 \\
3 & Water Temperature $\left(\mathrm{T}_{\mathrm{w}}\right)$ & 0.3 \\
4 & Water mass flow rate $\left(\dot{m}_{w}\right)$ & 0.41 \\
5 & Diameter Measurement $(\mathrm{d})$ & 0.113 \\
6 & Refrigerant thermal conductivity $(\mathrm{k})$ & 2.8 \\
7 & Dynamic viscosity $(\mu)$ & 6.47 \\
8 & Prandtl number $(\mathrm{Pr})$ & 0.283 \\
9 & Water specific heat $\left(\mathrm{C}_{\mathrm{w}}\right)$ & 0.024 \\
10 & Reynolds number $(\mathrm{Re})$ & 6.48 \\
11 & Heat Loads $(\mathrm{Q})$ & 0.489 \\
12 & Overall Heat Transfer Coefficients $(\mathrm{U})$ & 0.612 \\
13 & Nusselt number $(\mathrm{Nu})$ & 6.486 \\
14 & Heat Transfer Coefficients for water $\left(\mathrm{h}_{\mathrm{o}}\right)$ & 7.066 \\
15 & Condensation Heat Transfer Coefficients $\left(\mathrm{h}_{\mathrm{i}}\right)$ & 7.09 \\
\hline
\end{tabular}

where $\dot{m}_{\text {ref }}$ is the refrigerant mass flow rate, $h_{\text {ri }}$ and hro are the inlet and outlet specific enthalpy of saturated vapour refrigerant, respectively. In condensation zone can be calculated as follows:

$$
Q_{c o n}=\dot{m}_{r e f}\left(h_{r i}-h_{s l}\right)
$$

where $h_{s l}$ is the saturated liquid specific enthalpy of saturated vapor refrigerant.

The condensation HTCs in a tube $\left(\mathrm{h}_{\mathrm{i}}\right)$ can be determined using the following equation;

$$
h_{i}=\left[\frac{A_{i}}{A_{o} U_{o}}-\frac{A_{i}}{A_{o} h_{o}}-\frac{A_{i} \ln \left(d_{o} / d_{i}\right)}{2 \pi k_{t} L}\right]^{-1}
$$

where $A_{i}$ and $A_{\circ}$ are the inside and outside surface area of the tube, respectively. $U_{0}$ is the overall heat transfer coefficient and $h_{0}$ is the outside convective heat transfer coefficient. $\mathrm{K}_{\mathrm{t}}$ is the tube material thermal conductivity and $\mathrm{L}$ is the tube length. The outside convective heat transfer coefficient $\left(h_{0}\right)$ is given by the following equation;

$$
h_{o}=\frac{N u k_{w}}{d_{h}}
$$

where $d_{h}$ is the hydraulic diameter of the investigated tube $d_{h}=\left(D_{i}-d_{0}\right), k_{w}$ is the thermal conductivity of cooling water and $\mathrm{Nu}$ is the Nusselt number that can be determined by Dittus and Boelter equation as;

$$
N u=0.023 \operatorname{Re}^{0.8} \operatorname{Pr}^{0.4}
$$


The overall heat transfer coefficient $\left(\mathrm{U}_{0}\right)$ is defined as;

$$
U_{o}=Q_{c o n} /\left(A_{o} \Delta T_{l m, c o n}\right)
$$

However, $\Delta T_{\text {Imcon }}$ is the actual logarithmic mean temperature difference and can be calculated as follows:

$$
\Delta T_{\text {Im,con }}=\frac{\left(T_{r i}-T_{\text {wo }}\right)-\left(T_{s l}-T_{b}\right)}{\ln \left[\left(T_{r i}-T_{\text {wo }}\right) /\left(T_{s l}-T_{b}\right)\right]}
$$

where $T_{\mathrm{ri}}$ and $T_{\mathrm{ro}}$ are the inlet and outlet refrigerant temperatures, respectively. $T_{\mathrm{sl}}$ is the saturated liquid refrigerant temperature corresponding to condensation pressure. $\mathrm{T}_{\mathrm{b}}$ is the water temperature corresponding to saturated liquid refrigerant temperature which can be estimated as;

$$
T_{b}=T_{w o}-\frac{Q_{c o n}}{\dot{m}_{w} c_{w}}
$$

Condensation temperature difference can be estimated as follows,

$$
\Delta T_{\text {con }}=T_{r m}-T_{s i}
$$

where, $T_{r m}$ is the refrigerant mean temperature during the condensation zone (0.5 $\left.\left(T_{r i t} T_{s l}\right)\right)$ and $T_{s i}$ is the inner surface temperature facing to condensed refrigerant and can be calculated as,

$$
T_{s i}=0.5\left(T_{\text {wo }}+T_{b}\right)+Q_{c o n}\left[\ln \left(\frac{d_{o}}{d_{i}}\right) / 2 \pi k_{t} L+1 /\left(h_{o} A_{o}\right)\right]
$$

Validation of condensation HTCs of R-22 and R-417A is done using Dobson and Chato [13] and Boyko and Kruzhilin [15] correlations, which are given in equation (12) and (13) respectively:

Dobson and Chato [13];

$$
h_{i}=0.555\left[\frac{g \rho_{l}\left(\rho_{l}-\rho_{V}\right) k_{l}^{3} L H}{\mu_{l} d_{i} \Delta T_{\text {sat }}}\right]^{0.25}
$$

Boyko and Kruzhilin [15];

$$
h_{i}=0.024 \frac{k_{l}}{d_{i}} \operatorname{Re}_{i, l}^{0.8} \operatorname{Pr}_{i, i}^{0.43}\left[\frac{\sqrt{\left(\rho / \rho_{m}\right)}+\sqrt{\left(\rho / \rho_{m}\right)_{0}}}{2}\right]
$$

where 


$$
\sqrt{\left(\rho / \rho_{m}\right)_{i}}=1+x_{i}\left(\frac{\rho_{l}-\rho_{v}}{\rho_{v}}\right)
$$

and

$$
\sqrt{\left(\rho / \rho_{m}\right)_{o}}=1+x_{o}\left(\frac{\rho_{l}-\rho_{v}}{\rho_{v}}\right)
$$

\section{RESULTS AND DISCUSSIONS}

Condensation HTCs have been investigated under different parameters such as cooling water inlet temperature $\left(15: 30^{\circ} \mathrm{C}\right)$, cooling water velocity $(0.65: 0.85 \mathrm{~ms}-1)$, refrigerant saturation temperature $\left(40: 60^{\circ} \mathrm{C}\right)$, refrigerant type (R-22 and $\left.\mathrm{R}-417 \mathrm{~A}\right)$ and tube surface (smooth and micro-fin). First, a validation of the experimental apparatus with available data from the literature has been performed using R-22 and R-417A under different cooling water and refrigerant saturation temperatures for a smooth tube. Figure 3 shows a comparison between the experimental and predicted condensation HTCs using Dobson and Chato [13] and Boyko and Kruzhilin [15] correlations. Comparing present experimental data with Boyko and Kruzhilin [15] correlation yields that $73.9 \%$ and $69.6 \%$ of the condensation HTCs for R-22 and R$417 \mathrm{~A}$, respectively, lies between 0 and $-20 \%$ error. However, $87 \%$ and $69.6 \%$ of the experimental condensation HTCs results for R-22 and R-417A lies between 0 and $20 \%$ error as compared with Dobson and Chato correlation [13]. Generally, most of the present experimental data $(81.5 \%)$ for both refrigerants lies between $\pm 20 \%$ errors as compared with both correlations which confirm the capability of the test rig of producing reliable data. Reynolds number ranges from 4046 to 24773 during the validation experimental results.

\section{Effect of Refrigerant Saturated Vapor Temperature}

Figures 4 and 5 illustrate the effect of refrigerant saturated vapor temperature on the condensation temperature difference and condensation HTCs, respectively, for R417A inside a smooth tube while other parameters remain constant. Fig. 4 shows variation of condensation temperature difference with refrigerant saturated vapor temperature. In fact, for constant cooling water inlet temperature and cooling water velocity, the outer surface temperature of the inner tube remains constant. Therefore, the condensation temperature difference increases as the refrigerant saturated vapor temperature increases as seen in Fig. 4.

However, condensation HTCs are inversely proportional to the condensation temperature difference. This because the condensation film thickness increases and consequently the condensation thermal resistance increases as the condensation temperature difference increases. The condensation HTCs decrease as the saturation refrigerant temperature increases as seen in Fig. 5. It should be mentioned that, the condensation HTCs decrease by $58 \%$ as the saturation refrigerant temperature increases from 40 to $60^{\circ} \mathrm{C}$ at constant cooling water inlet temperature of $25^{\circ} \mathrm{C}$. 


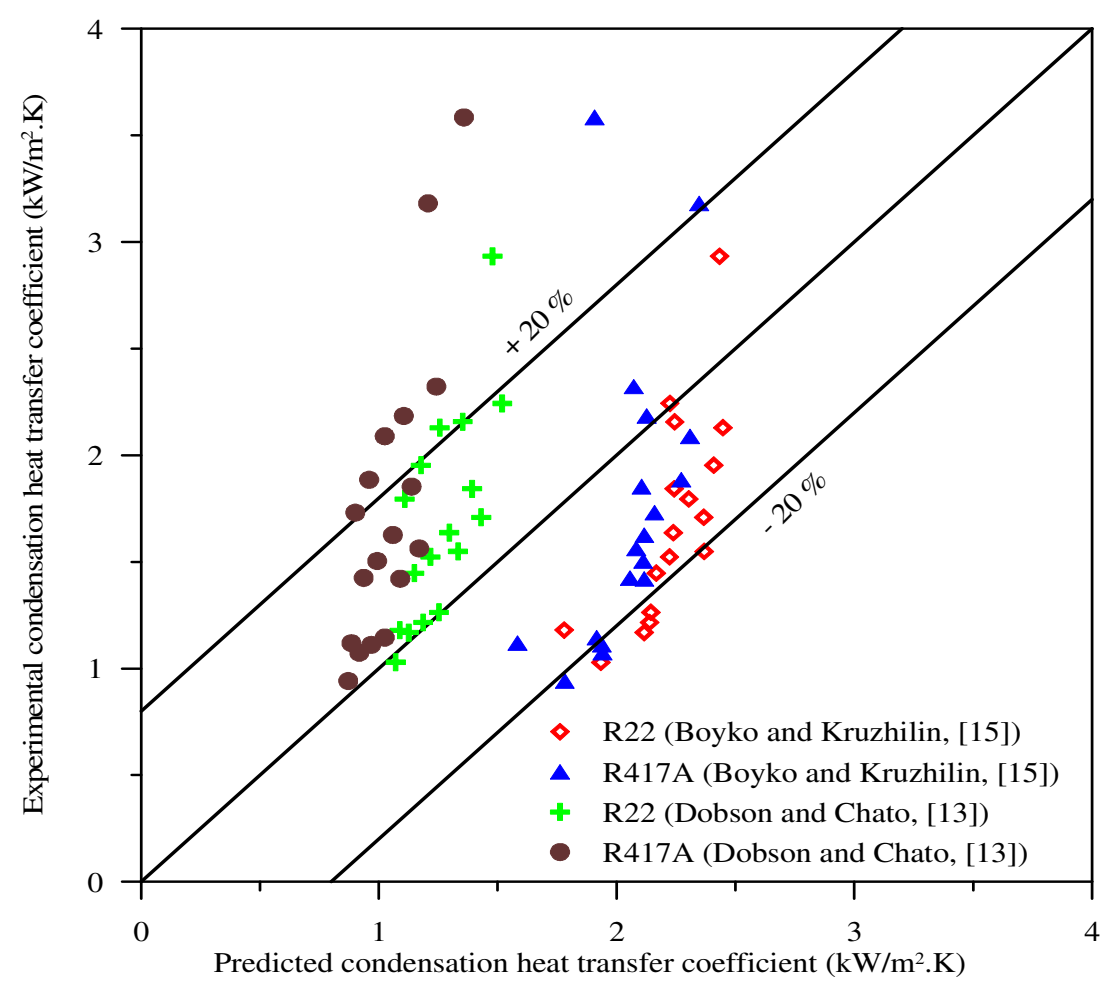

Fig. 3. Comparison between experimental condensation heat transfer coefficient and predicted condensation heat transfer coefficient of R-22 in a smooth tube.

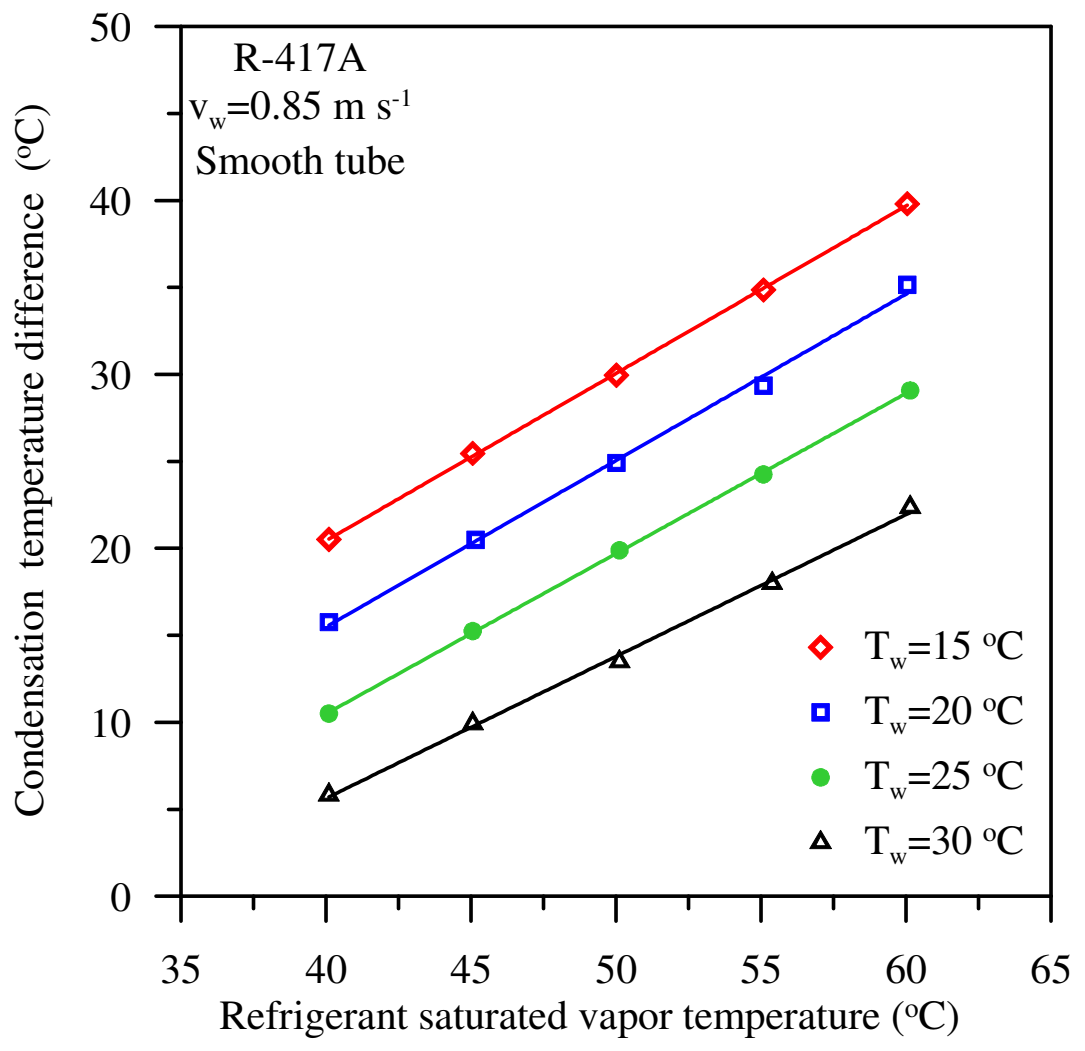

Fig. 4. Condensation temperature difference versus refrigerant saturated vapor temperature at different water temperatures. 


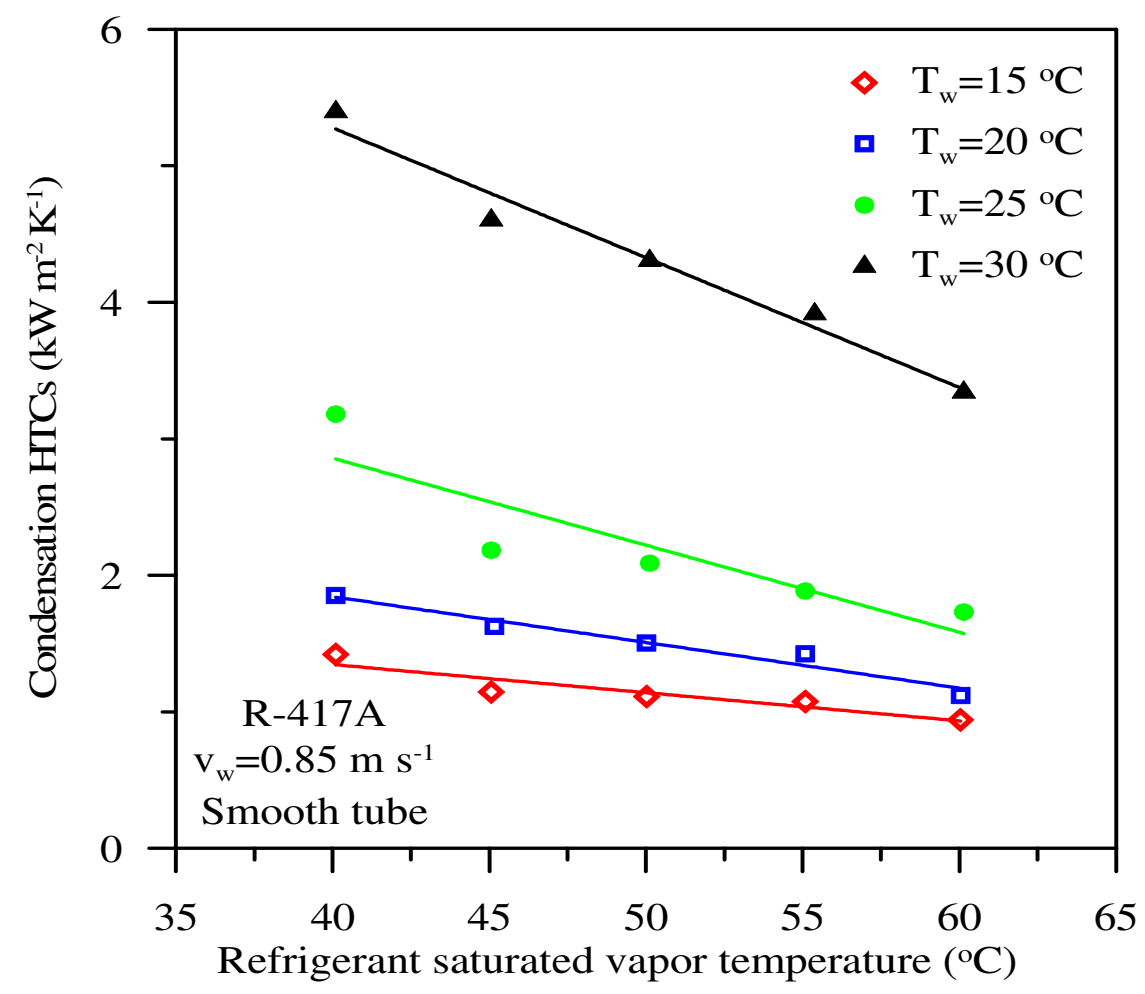

Fig. 5. Condensation HTCs against refrigerant saturated vapor temperature at different water temperatures.

\section{Effect of Cooling Water Inlet Temperature}

Influence of cooling water inlet temperature on condensation temperature difference and condensation HTCs are also shown in Figs. 4 and 5, respectively. Cooling water velocity is fixed at $0.85 \mathrm{~ms}^{-1}$ while the cooling water inlet temperature changed from 15 to $30^{\circ} \mathrm{C}$. In fact, as the cooling water inlet temperature increases the surface temperature (faced to the condensation refrigerant) increases at constant refrigerant saturated vapor temperature. Hence, the condensation temperature difference decreases as observed from Fig. 4. It should be mentioned that, the decrease in condensation temperature difference becomes higher at the higher cooling water inlet temperature. At refrigerant saturated vapor temperature of $60^{\circ} \mathrm{C}$, as the cooling water inlet temperature increases from 15 to $20^{\circ} \mathrm{C}$ the condensation temperature difference decreases by $5 \mathrm{~K}$. However, this value increased to $7 \mathrm{~K}$ when the coolant inlet temperature increases from 25 to $30^{\circ} \mathrm{C}$.

As mentioned before, a thinner condensation film is resulting at lower condensation temperature difference and this led to a higher condensation HTCs as shown in Fig. 5. As the cooling water inlet temperature changed from 15 to $30^{\circ} \mathrm{C}$, the condensation HTCs increase from 1.05 to $3.3 \mathrm{kWm}^{-2} \mathrm{~K}^{-1}$ at refrigerant saturated vapor temperature of $60^{\circ} \mathrm{C}$. It should be pointed out; the influence of the cooling water inlet temperature becomes more significant at lower refrigerant saturated vapor temperature due to the high heat flux. Condensation HTCs increase from 1.6 to $5.6 \mathrm{kWm}^{-2} \mathrm{~K}^{-1}$ at refrigerant 
saturated vapor temperature of $40 \mathrm{bbc}^{\circ} \mathrm{C}$ for the same cooling water inlet temperature range.

\section{Effect of Cooling Water Velocity}

Variations of condensation temperature difference and condensation HTCs versus refrigerant saturated vapor temperature for micro-fin and smooth tubes at different cooling water velocities are shown in Figs. 6 and 7, respectively. Clearly, condensation temperature difference increases as the cooling water velocity increases. This trend can attributed to the higher heat flux corresponding to higher cooling water velocity which led the surface temperature to decrease. Hence, condensation temperature difference increases for a constant refrigerant saturated vapor temperature.

Figure 7 illustrates the influence of cooling water velocity on the condensation HTCs for smooth and micro-fin tubes. Obviously, the condensation HTCs are inversely proportional to the cooling water velocity. As the coolant fluid velocity increases from 0.65 to $0.95 \mathrm{~ms}^{-1}$ the condensation HTCs decrease by $20 \%$ at refrigerant saturated vapor temperature of $50^{\circ} \mathrm{C}$ for smooth tube. This is attributed mainly to the lower condensation temperature difference corresponding to the higher cooling water velocity.

\section{Effect of Tube Configuration}

Effect of tube configurations on the condensation temperature difference and condensation HTCs can be explored from Fig. 6 and Fig. 7, respectively. Smooth and micro-fin tube configurations have been tested under variable cooling water velocities (0.65 and $\left.0.95 \mathrm{~ms}^{-1}\right)$ and different refrigerant saturated vapor temperatures $\left(40-60^{\circ} \mathrm{C}\right)$. Variation of condensation temperature difference versus refrigerant saturated vapor temperature is shown in Fig. 6. Clearly, a smooth tube has higher condensation temperature difference than micro-fin tube due to the increase in heat flux occurring in the micro-fin tube. As the heat flux increases the surface temperature increases which led the condensation temperature difference to decrease at constant refrigerant saturated vapor temperature.

Figure 7 shows variation of condensation HTCs against refrigerant saturated vapor temperature for smooth and micro-fin tubes. Obviously, condensation HTCs are higher in case of micro-fin tube as a result of condensation temperature difference decreasing. This is explained by the fact that the condensate film thickness decreases when the condensation temperature difference decreases, thereby the condensation thermal resistance decreases causing the condensation HTCs to increase. It should be noted that, condensation HTCs increase by $36 \%$ and $73 \%$ for micro-fin tube as compared with smooth tube at cooling water velocity 0.65 and $0.95 \mathrm{~ms}^{-1}$ respectively at refrigerant saturated vapor temperature of $50{ }^{\circ} \mathrm{C}$. Hence, using of micro-fin tube has a significant effect on the condensation HTCs especially at higher cooling water velocity. 


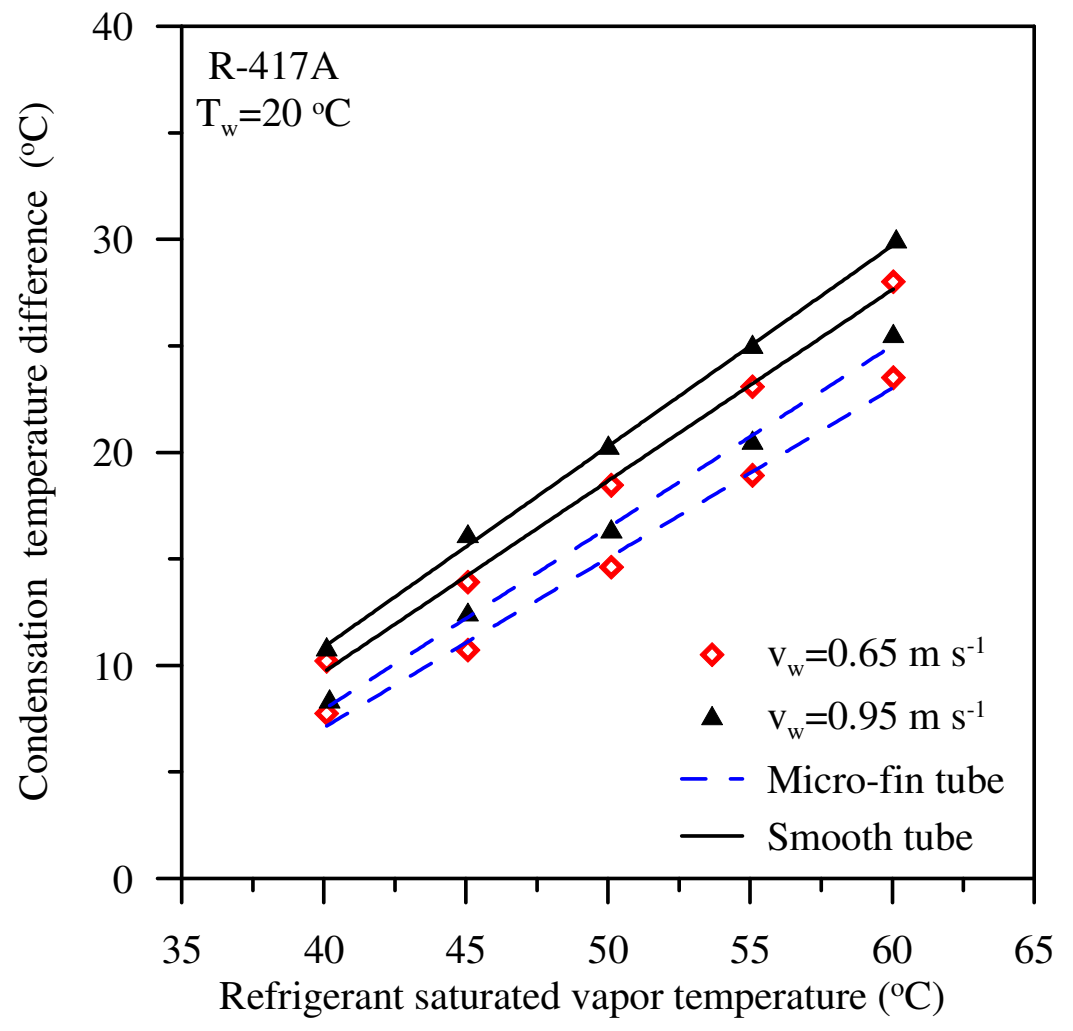

Fig. 6. Variation of condensation temperature difference with refrigerant saturated vapor temperature at different water velocities for smooth and micro fin tubes.

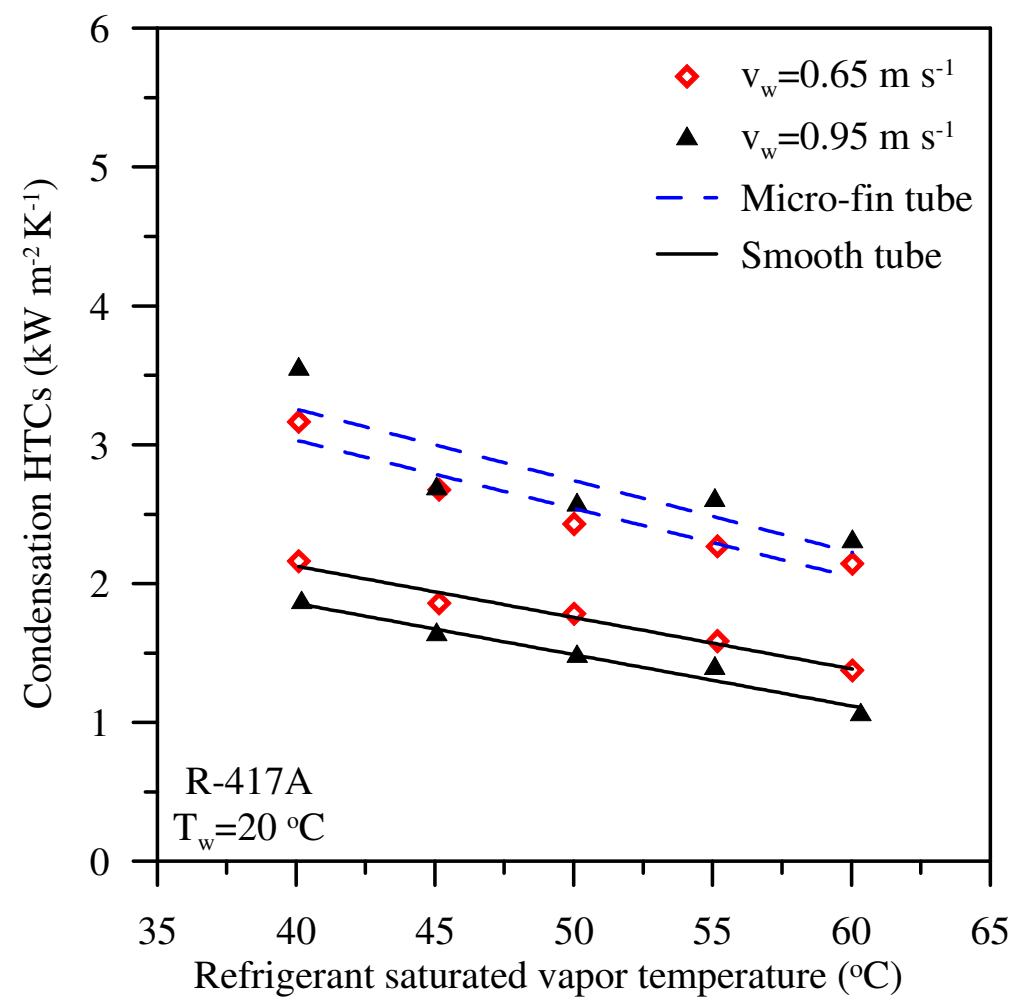

Fig. 7. Variation of condensation HTCs with refrigerant saturated vapor temperature at different water velocities for smooth and micro fin tubes. 


\section{Comparison between R-22 and R-417A}

Condensation HTCs of R-417A inside horizontal smooth tube are compared with those of R-22 at different refrigerant saturated vapor temperature for various cooling water inlet temperatures and constant cooling water velocity on the same test rig. Figure 8 shows a comparison between condensation temperature difference for R-22 and R417A for different cooling water inlet temperatures. Clearly, R-22 has higher temperature difference than $\mathrm{R}-417 \mathrm{~A}$ at any refrigerant saturated vapor temperature and cooling water inlet temperature. This can attributed to the high heat flux of R-22 which is resulting from its high condensation latent heat (See Fig. 9).

Figure 10 shows a comparison between condensation HTCs for R-22 and R-417A for different cooling water inlet temperatures. In general, R-22 achieves higher HTCs than $\mathrm{R}-417 \mathrm{~A}$ for the same condensation temperature difference. The fact that, the condensation HTCs of R-22 are much higher than those of non-azeotropic mixtures (e.g. R-417A) is due to its superior thermodynamic properties. The difference in condensation HTCs between R-22 and R-417A decreases at higher refrigerant saturated vapor temperature and lower cooling water inlet temperature. It should be pointed out, condensation HTCs are lowered by $47.6 \%$ and $35.5 \%$ at refrigerant saturated vapor temperature of $40^{\circ} \mathrm{C}$ and $60^{\circ} \mathrm{C}$ at cooling water inlet temperature of $30{ }^{\circ} \mathrm{C}$. However, these values changed to be $32.3 \%$ and $15.3 \%$ at cooling water inlet temperature of $15^{\circ} \mathrm{C}$. Similar results have been observed by Fernández-Seara et al. [16] for condensation on CuNi turbo $\mathrm{C}$ tubes. They reported that overall condensation HTC for R-417A is lowered by $65-76 \%$ than HTCs for R-22.

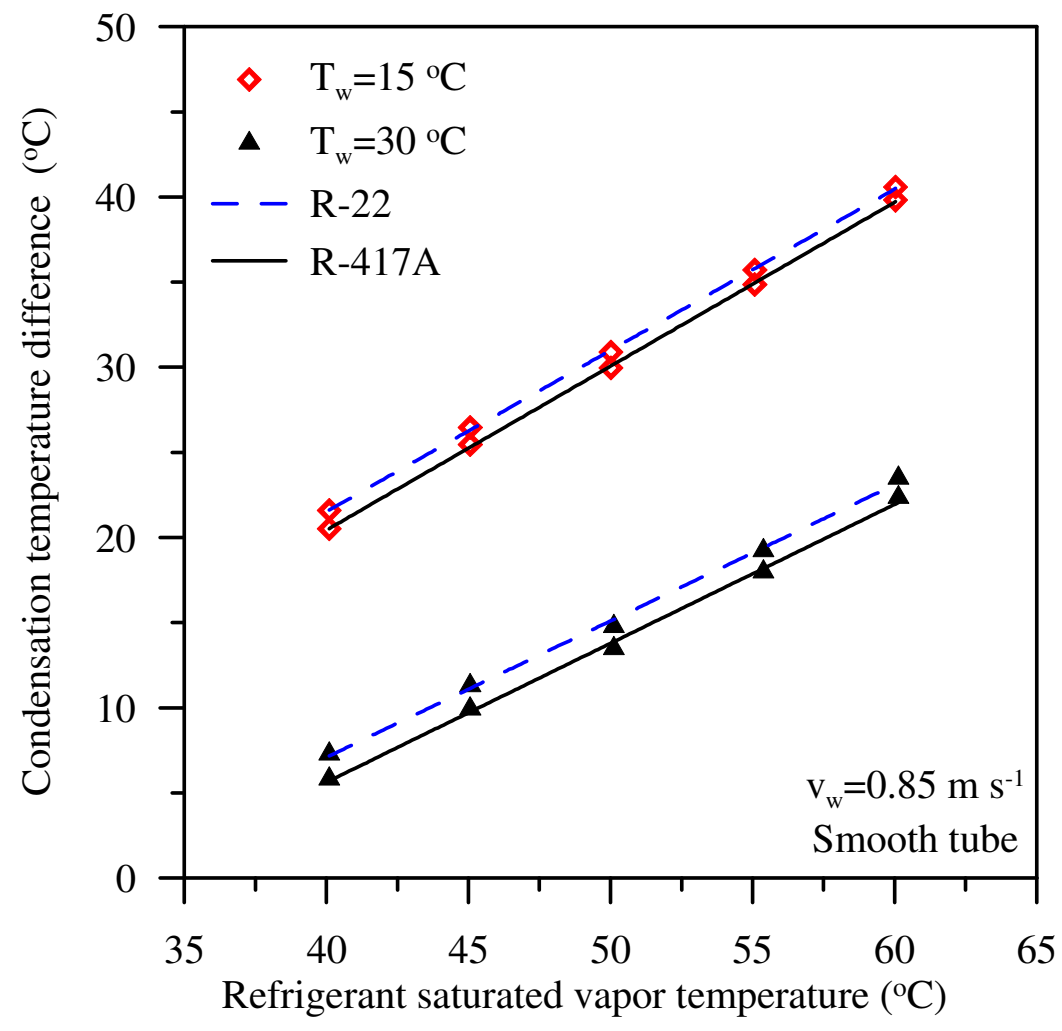

Fig. 8. Condensation temperature difference with refrigerant saturated vapor temperature at water velocity $0.85 \mathrm{~ms}^{-1}$ for R-22 and R-417A in a smooth tube. 


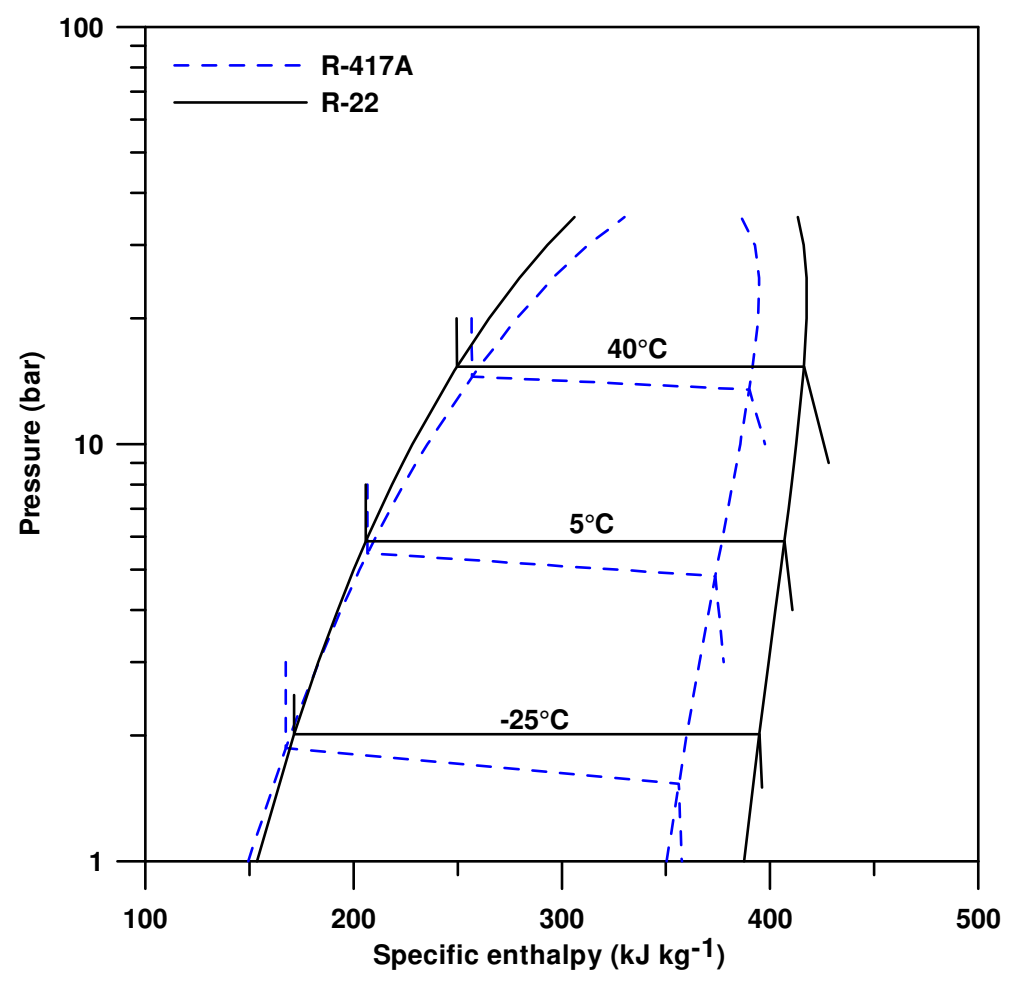

Fig. 9. Pressure - specific enthalpy diagram of the R-22 and R-417A.

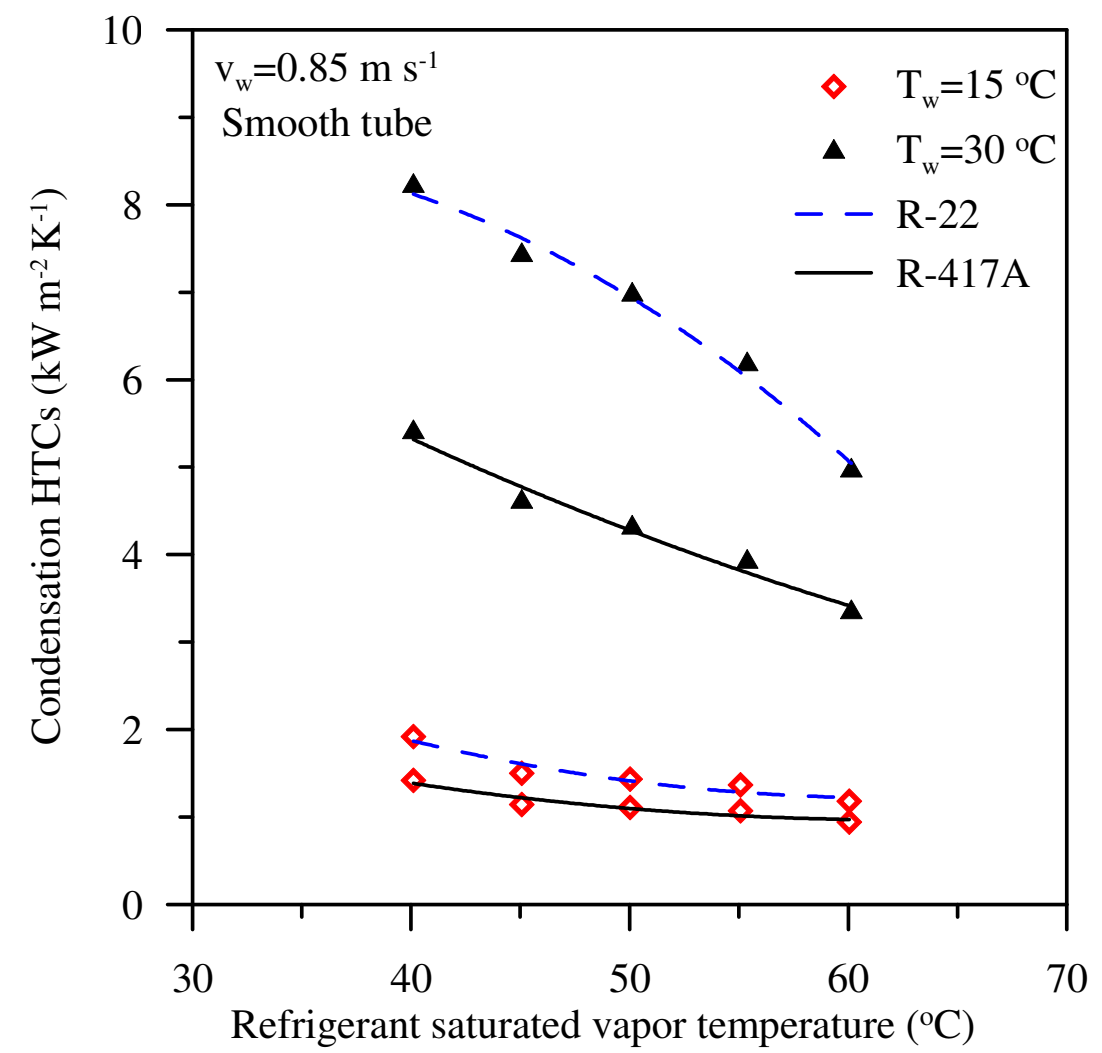

Fig. 10. Condensation HTCs with refrigerant saturated vapor temperature at water velocity $0.85 \mathrm{~m} \mathrm{~s}-1$ for $\mathrm{R}-22$ and $\mathrm{R}-417 \mathrm{~A}$ in a smooth tube. 
These experimental results also reflect that the mixtures composition has a strong influence on the condensation HTCs.

\section{CONCLUSIONS}

In this paper, condensation HTCs of refrigerant R-417A as an alternative to R-22 inside smooth and micro-fin tubes have been investigated under different operating conditions such as refrigerant saturated vapor temperature, cooling water inlet temperature and cooling water velocity. Based on the reported results, the following conclusions are drawn;

- Predicted condensation HTCs gives a fairly agreement with different correlations from the literature. Actually, $81.5 \%$ of the predicted condensation HTCs are within $\pm 20 \%$ error as compared with Dobson and Chato [13] and Boyko and Kruzhilin [15] correlations.

- Cooling water inlet temperature has a significant impact on condensation HTCs. It should be pointed out that as the cooling water inlet temperature changed from 15 to $30^{\circ} \mathrm{C}$ the condensation HTCs increase three times whatever the refrigerant saturated vapor temperature.

- Condensation HTCs can be enhanced by either increasing the cooling water inlet temperature or decreasing the cooling water velocity or refrigerant saturated vapor temperature.

- Using a micro-fin tube, condensation HTCs increase by $36 \%$ and $73 \%$ for microfin tube at cooling water velocity 0.65 and $0.95 \mathrm{~m} \mathrm{~s}^{-1}$ respectively at refrigerant saturated vapor temperature of $50^{\circ} \mathrm{C}$.

- The difference in condensation HTCs between R-22 and R-417A decreases at higher refrigerant saturated vapor temperature and lower cooling water inlet temperature.

- Using the drop-in refrigerant R-417A, condensation HTCs are lowered by $47.6 \%$ and $35.5 \%$ at refrigerant saturated vapor temperatures of $40^{\circ} \mathrm{C}$ and $60^{\circ} \mathrm{C}$ at cooling water inlet temperature of $30^{\circ} \mathrm{C}$. Therefore, an enhancement technique should be used to compensate the decreasing in HTCs.

\section{REFERENCES}

[1] World Meteorological Organization, Montreal protocol on substances that deplete the ozone layer report. WMO Bull 37, pp. 94-97, 1988.

[2] World Meteorological Organization, Scientific assessment of ozone depletion. WMO Global Ozone Research and Monitoring Project Report Geneva 37, 1995.

[3] S. Devotta, A.S. Padalkar, and N.K. Sane, "Performance assessment of HCFC22 window air conditioner retrofitted with R-407C", Applied Thermal Engineering, 25, pp. 2937-2949, 2005. 
[4] M. Uchida, M. Itoh, N. Shikazono, and M. Kudoh, "Experimental study on the heat transfer performance of a zeotropic refrigerant mixture in horizontal tubes" Proceedings of 1996 international refrigerant conference, Purdue, pp. 133138, 1996.

[5] H. Wijaya and M.W. Spatz, "Two-phase flow condensation heat transfer and pressure drop characteristics", Proceedings of international refrigerant conference, Purdue, pp. 305-310, 1994.

[6] M.H. Kim and J.S. Shin, "Condensation heat transfer of R-22 and R410A in horizontal smooth and micro-fin tubes", International Journal of Refrigeration Vol. 28, pp. 949-957, 2005.

[7] D. Jung, Y. Cho and K. Park, "Flow condensation heat transfer coefficient of R22, R134a, R407C, and R410A inside plain and micro-fin tubes", International Journal of Refrigeration, Vol. 27, pp. 25-32, 2004.

[8] C.A. Infante Ferreira, T.A. Newell, J. C. Chato and X. Nan, "R404A condensing under forced flow conditions inside smooth, micro-fin and cross-hatched horizontal tubes", International Journal of Refrigeration, Vol. 26, pp. 433-441, 2003.

[9] S. Sapali, and P.A. Patil, "Heat transfer during condensation of HFC-134a and R-404A inside of a horizontal smooth and micro-fin tube", Experimental Thermal and Fluid Science, Vol. 34, pp. 1133-1141, 2010.

[10] Z. Yang and X. Wu, "Review retrofits and options for the alternatives to HCFC22", Energy, Vol. 59, pp.1-21, 2013.

[11] C. Aprea, R. Mastrullo and C. Renno, "An analysis of the performances of a vapour compression plant working both as a water chiller and a heat pump using R-22 and R-417A", Applied Thermal Engineering, Vol. 24, pp. 487-499, 2004.

[12] X. Boissieux, M.R. Heikal and R.A. Johns, "Two-phase heat transfer coefficients of three HFC refrigerants inside a horizontal smooth tube, part II: condensation", International Journal of Refrigeration, Vol. 23, pp. 345-352, 2000.

[13] M. Dobson and J. Chato, "Condensation in smooth horizontal tubes", Journal of Heat Transfer, Vol. 120, pp.193-213, 1998.

[14] M.M Shah, "A general correlation for heat transfer during film condensation inside pipes", International Journal Heat and Mass Transfer, Vol. 22, pp. 54756, 1979.

[15] L.D. Boyko and G.N. Kruzhilin, "Heat transfer and hydraulic resistance during condensation of steam in a horizontal tube and in a bundle of tubes", International Journal of Heat and Mass Transfer, Vol. 10, pp. 361-373, 1967.

[16] J. Fernández-Seara, F.J. Uhía, R. Diz, and J.A. Dopazo, "Vapour condensation of R22 retrofit substitutes R417A, R422A and R422D on CuNi turbo C tubes", International Journal of Refrigeration, Vol. 33, pp. 148 - 157, 2010. 